\title{
Analyzing and Modeling Temporal Disease Progress of Barley yellow dwarf virus Serotypes in Barley Fields
}

\author{
F. Leclercq-Le Quillec, M. Plantegenest, G. Riault, and C. A. Dedryver
}

INRA/ENSA, Unité Mixte de Recherche Biologie des Organismes et des Populations appliquée à la Protection des Plantes (BiO3P), Domaine de la Motte B.P. 35327, F-35653 Le Rheu cedex, France. Current address of F. Leclercq-Le Quillec: CIRAD, BP 20, 97408 Saint-Denis Messagerie, La Réunion, France. Accepted for publication 27 April 2000.

\begin{abstract}
Leclercq-Le Quillec, F., Plantegenest, M., Riault, G., and Dedryver, C. A. 2000. Analyzing and modeling temporal disease progress of Barley yellow dwarf virus serotypes in barley fields. Phytopathology 90:860-866.

Population dynamics of Padi avenae (PAV), Macrosiphum avenae (MAV), and Rhopalosiphum padi (RPV) virus serotypes of Barley yellow dwarf virus (BYDV) and of their main aphid vectors were studied in winter barley (Hordeum vulgare) fields for three successive years in western France. An epidemiological model of the spread of viruses in the field was developed based on vector populations as forcing variables and the population dynamics of each virus serotype. This model accurately simulated the kinetics of the epidemic for PAV serotypes, which are the most common ones. For RPV and to some extent for MAV, the results were less satisfactory. The occurrence and spread of PAV and MAV serotypes in the field was clearly and easily related to that of their main

consistent relationships with the dynamics of their vectors. Incidence of PAV in 1989 to 1990 and 1990 to 1991 showed a bimodal distribution, with maximums in fall (December) and spring (May) that were linked to fall infestations by $R$. padi and spring infestations by three (R. padi, Sitobion avenae, and Metopolophium dirhodum) or two (S. avenae and M. dirhodum) aphid species. In 1991 to 1992, the PAV infection curve was monomodal and mainly due to a primary spread of the virus by very large populations of alate $R$. padi. MAV incidence was low in fall and winter and reached a maximum in spring 1990 and 1991 related to the occurrence of $S$. avenae and $M$. dirhodum. RPV incidence was low every year, despite the abundance of its vector, $R$. padi. Mixed infections were more frequent than expected by chance and were assumed to be partly related to heterologous encapsidation. The occurrence of each serotype is discussed in relation to the time of crop infection and possible damage.
\end{abstract} vector species. Conversely, the spread of RPV serotypes showed no

Barley yellow dwarf virus (BYDV) is one of the most severe cereal diseases in the world. It is caused by viruses of the family Luteoviridae (5) and transmitted persistently by aphid species living on Poaceae with a variable degree of vector specificity (40). The viruses that cause Barley yellow dwarf disease BYD have been characterized by their principal aphid vectors $(41,42)$, serological properties (43), pathogenicity $(11,12,13)$, and nucleic acid size and sequence homology $(8,47)$. In Western Europe three viruses are common: Padi avenae virus (PAV), Macrosiphum avenae virus (MAV), and Rhopalosiphum padi virus (RPV) $(30,38)$. RPV is mainly transmitted by Rhopalosiphum padi, MAV is transmitted by Sitobion avenae and Metopolophium dirhodum, and PAV is transmitted nonspecifically by the three aphid species $(37,38)$. Although specificity varies somewhat between geographic areas, viral isolates, and aphid clones $(4,16,18,31,45)$, the distribution of each serotype is largely dependent on its main vector (21). Also, the specificity of transmission results in changes in the importance of the three serotypes in crops between fall and spring because of changes in relative frequencies of their aphid vectors (39). Crop damage depends on the cultivar or variety used (1) but also on the virus (1) and isolate $(2,33)$ involved and their periods of infection and dissemination. Therefore, population dynamics of the three viruses has to be taken into consideration for any risk assessment.

The incidence of BYD in field crops depends mainly on the spatiotemporal dynamics of the viruses from time of cereal emer-

Corresponding author: C. A. Dedryver; E-mail address: cdedryve@rennes.inra.fr

Publication no. P-2000-0526-02R

(C) 2000 The American Phytopathological Society
Additional keywords: primary infections, secondary spread. gence to ripening. Viral dynamics involve primary infection, i.e., the introduction of virus by mobile immigrant alate aphids flying into a crop from some distance (36), and secondary spread within the crop due to less mobile apterous aphids produced in the crop as progeny of previous alate immigrants $(25,27)$. The extent of secondary spread is presumed to be mainly controlled by the influence of weather on the vectors and their enemies (38). On winter cereal, in areas with early and severe winters, such as continental climates, the secondary spread of viruses is generally disrupted during fall, because aphid vectors are killed by frost. Consequently, final crop damage can be forecast accurately by assessing only primary infection (37). In more temperate zones, mild autumns and winters allow vectors to overwinter anholocyclically in cereal crops (19) and, consequently, permit secondary spread of the viruses. In these areas, disease incidence can be much higher than predicted when monitoring primary infection alone (26).

The time of infection in relation to plant phenology has economic implications by restricting the time for an epidemic to develop. The younger the crop when infected, the greater the loss (22), because fall-infected barley plants have poor tillering and become highly susceptible to winter frost. In contrast, spring infections, especially those occurring after stem extension, do not cause much damage. Gildow and Franck (9) confirmed that early infection of oat with a PAV variant affected yield more significantly than infections occurring slightly later.

Much of the previous work on BYD epidemiology has been devoted to the relationships between the flight phenology of the vectors and primary infections and the role of graminaceous crops as vector and virus reservoirs $(17,38)$. Paradoxically, there has been little work on the secondary spread of viruses in cereal fields and on its relationships with vector multiplication and interplant 
movement. Exceptions include theoretical approaches $(25,32)$ and some ecological studies taking into account field samples collected in different seasons $(3,10)$, like that of Ranieri et al. (39), who surveyed monthly serotype progress in wheat fields near Mexico but without reference to vector populations and without modeling.

The present work focuses on the temporal epidemiology of different BYDV serotypes and their vectors in barley fields in western France and is the first attempt to model disease progress curves with respect to serotype.

In western France, the mild oceanic climate generally allows aphids to overwinter in winter barley, winter wheat, and cereal volunteers (7), and severe damage caused by BYD can occur in winter cereals (29). Aerial dispersal of viruses during the year and its consequences on primary infection rate of winter barley have been reported: PAV is predominant in flying aphid populations caught in the fall, whereas PAV and MAV are equally abundant in spring populations (30). The present investigations were carried out to (i) provide field-based knowledge of BYDV secondary spread by studying the disease incidence pattern changes for three successive years in barley fields with respect to time and BYDV serotype, and (ii) analyze relationships between the occurrence of serotypes and the occurrence of their vectors. This work also aimed to demonstrate that the spread of BYDV serotypes is directly connected to the population dynamics of their vectors and can be accurately simulated using a simple model with aphid densities and temperature as exogenous variables.

\section{MATERIALS AND METHODS}

Experimental trials. Experiments were carried out over three cropping seasons, from September 1989 to July 1992, in a winter barley field (cv. Express) at the INRA Research Station in Le Rheu, Brittany, western France. Fields were sown, respectively, on 13 September 1989, 1 October 1990, and 23 September 1991, and plants emerged 2 weeks after the sowing date. Crops were harvested on 13 July 1990, 17 July 1991, and 15 July 1992. In the following text, fall includes October, November, and December; winter includes January, February, and March; and spring includes April, May, and June.

Aphid and virus sampling. Viruses and aphids were monitored at 14-day intervals from crop emergence to mid-November and at monthly intervals during winter and spring. For each date, 3 samples of 30 contiguous barley plants were randomly selected in each of four $50 \times 12$-m plots in a 2 -ha field. The number of plants infested by each aphid species (mainly $R$. padi, S. avenae, and $M$. dirhodum and more rarely $R$. maidis) was assessed in the field. All sampled plants were subsequently cut, placed individually in plastic bags, washed and stored at $-20^{\circ} \mathrm{C}$ until tested for BYDV infection by enzyme-linked immunosorbent assay (ELISA). Because BYDV infection is systemic, only one tiller per plant was randomly collected after tillering for virus diagnosis.

ELISA. Each frozen plant or tiller was tested by ELISA. Polyclonal and monoclonal immunoglobulins (Ig) were used in a standard indirect sandwich ELISA procedure, as described by Torrance et al. $(35,46)$.

MAV and RPV polyclonal antisera supplied by H. Lapierre (INRA, Versailles, France) and one PAV polyclonal antiserum (Bioreba AG, Basle, Switzerland) were used for coating. Plates were incubated for $4 \mathrm{~h}$ at $37^{\circ} \mathrm{C}$. Sap from $0.3 \mathrm{~g}$ of leaf material was extracted in $5 \mathrm{ml}$ of PBST-PVP (phosphate-buffered saline, $0.5 \%$ Tween $20,2 \%$ polyvinylpyrrolidone) and the antigen (200 to $250-\mu$ l aliquots) was incubated overnight at $4{ }^{\circ} \mathrm{C}$. Monoclonal antibodies Mac91, Mac92, and Maff2 produced by L. Torrance (MAFF, ADAS Central Science Laboratory, Harpenden, England) against PAV-, RPV-, and MAV-like isolates respectively, were added after dilution in PBST-PVP $(1 \mu \mathrm{g} / \mathrm{ml})$, and plates were incubated at $37^{\circ} \mathrm{C}$ for $2 \mathrm{~h}$. IgG antirat $(1 / 2,000$; Sigma-Aldrich Chemical Co., Saint Quentin Fallavier, France) conjugated to al- kaline phosphatase was added and incubated at $37^{\circ} \mathrm{C}$ for $2 \mathrm{~h}$. Substrate (p-nitrophenylphosphate) was added, and the optical density (OD) was measured at $405 \mathrm{~nm}$ with a MR5000 spectrophotometer (Dynatech Laboratories, Chantilly, VA) after 1 to $2 \mathrm{~h}$ incubation at room temperature. Samples were considered positive when OD values were more than three times the mean values of uninfected controls.

Weather. Temperature data were obtained from the INRA meteorological station adjacent to the experimental fields. Only mean temperatures at 2-m above ground level were used and were converted to degree-days (baseline $0^{\circ} \mathrm{C}$, threshold for aphid development) from the first sampling date of each year.

Analysis of aphid and disease progress curves. An epidemiological model of the spread of viruses in the field was developed based on the number of vectors and population dynamics of each virus serotype. The basic structure of the model was similar to classical susceptible-infectious-removed models used in human epidemiology (28). The susceptible component was made up of living barley plants $(N)$. The infectious component was split into three serotypes (PAV, MAV, and RPV). The removed component represents mortality due to the PAV serotype only, because in winter barley fields only plants infected during fall could be killed in notable proportion by BYDV, and in our samples PAV was involved in $90 \%$ of these fall infections. This mortality is assumed to occur at a constant rate $(\mu)$ after a delay of $h$ after infection. It therefore, is proportional to the number of infected tillers by PAV at time $t-h$. Because the model assumes that infections occur independently, this mortality also affects tillers coinfected by PAV and other serotypes proportionally to their ratio in the population. The infection rates are assumed to be proportional both to the number of uninfected plants and to the proportion of plants infested by aphids of each transmission group $\left(A_{P}=\mathrm{PAV}: M\right.$. dirhodum $+S$. avenae $+R$. padi $; A_{M}=$ MAV: $M$. dirhodum $+S$. avenae; $A_{R}=\mathrm{RPV}: R$. padi). The transmission potential of these groups, set initially to an index of 1 , was increased linearly with the number of neighboring infectious plants of the given serotype through a coefficient $(c)$ common to the three groups for parsimonious reasons. The relative infectivity rates of each group of vectors are denoted as $\rho_{1}, \rho_{2}$, and $\rho_{3}$. The complete set of equations is written as follows:

$$
\begin{gathered}
d N / d t=-\mu P_{V}(t-h) \\
d P_{V} / d t=\rho_{1} A_{P}\left(1+c P_{V}\right)\left(N-P_{V}\right)-\mu P_{V}(t-h) \\
d M_{V} / d t=\rho_{2} A_{M}\left(1+c M_{V}\right)\left(N-M_{V}\right)-\mu P_{V}(t-h) M_{V} / N \\
d R_{V} / d t=\rho_{3} A_{R}\left(1+c R_{V}\right)\left(N-R_{V}\right)-\mu P_{V}(t-h) R_{V} / N
\end{gathered}
$$

where $N, P_{V}, M_{V}$, and $R_{V}$, the state variables, are, respectively, the numbers of living plants and plants infected by the three serotypes at time $t$. $A_{P}, A_{M}$, and $A_{R}$, as defined above, are treated as forcing variables, and $\rho_{1}, \rho_{2}$, and $\rho_{3}$ are the relative rates of infection. Parameter $h$ is the mean delay from infection to death caused by the PAV serotype. The system cannot be differentiated analytically because it involves both a delay variable and external driving variables. Three curves were fitted for viral disease development for each year: $\operatorname{Vir} P_{V}(t)=P_{V}(t) / N(t) ; \operatorname{Vir} M_{V}(t)=M_{V}(t) / N(t)$; and $\operatorname{Vir}_{V}(t)=R_{V}(t) / N(t)$. Time $t=0$ was the date of first observation. Initial conditions were not submitted to the fitting process but set to the first sampling value.

Population dynamics of aphids were not modeled. The proportion of plants infested by the three aphid species over time (expressed as degree-days) was estimated by sampling as explained above. Because the model requires a continuous input of aphid incidence on plants, the vector data collected in the field were smoothed and interpolated (daily estimate) by a fourth-degree polynomial, chosen as the best compromise between smoothness and accuracy in the set of data. To ensure that the interpolated values remained in a range from 0 to 1 , the sampling data were trans- 
formed to arcsine squareroot $(x)$, and the polynomial was fitted by the least-square method to the transformed data. The reverse function was applied to get the estimated values. The decrease in aphid activity during winter was not explicitly introduced in the model but was taken into account by measuring time on a degree day scale.
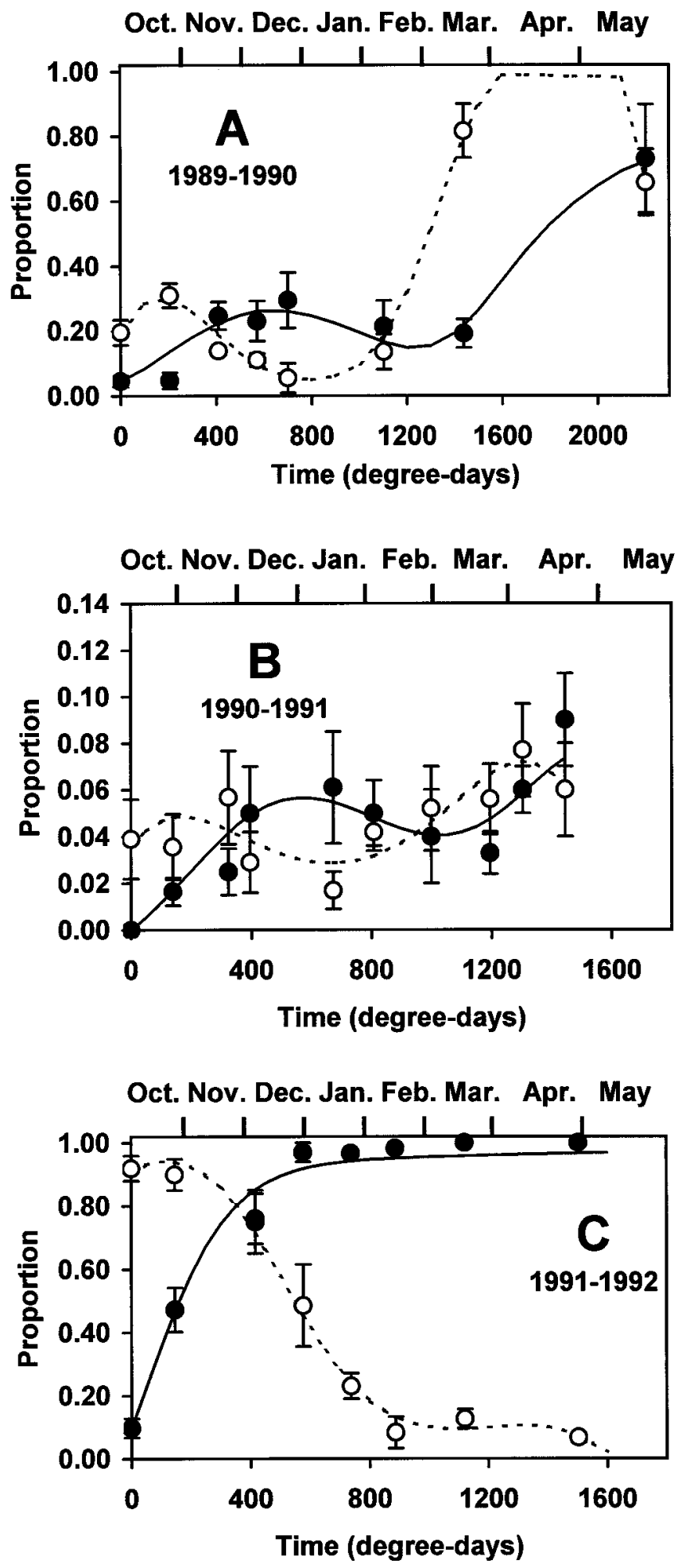

Fig. 1. Proportion of plants infected by Padi avenae virus (PAV) serotypes observed (black circles) and fitted (solid line) by the epidemiological model (equations in text). Proportion of plants infested by at least one of the three vector species, Rhopalosiphum padi, Sitobion avenae, and Metopolophium dirhodum, observed (hollow circles) and interpolated (dashed line) by a fourth-degree polynomial. Upper abcissa: time in months; lower abcissa: time in degree days. Bars are standard deviations.
Numerical analysis. The software package SimuSolv (Dow Chemical, Midland, MI) was used to fit the model to field data. Differential equations were solved numerically by a composite Runge-Kutta algorithm of order five method. The fit was obtained by a multivariate likelihood maximization function using a NewtonRaphson method. Error terms were assumed to follow a multivariate normal distribution.

Analyses of mixed infections. For the years 1989 to 1990 and 1990 to 1991, independence of the infections by pairs of serotypes was checked using a $\chi^{2}$ test calculated on the observed numbers of plants belonging to each category (healthy, infected by serotype A, infected by serotype B, and infected by both serotypes).

\section{RESULTS}

Dynamics of viruses and vectors. In any 1 year, overall infection and PAV infection curves were similar, showing the predominance of PAV serotypes in the pathosystem. For this reason overall infection curves are not shown. Figures 1 to 3 illustrate data obtained for each viral serotype; the 3 years display contrasting patterns, with high levels of infection in 1989 to 1990 and 1991 to 1992 and low levels of infection in 1990 to 1991.

The dynamics of PAV serotypes were bimodal in 1989 to 1990 and 1990 to 1991 (Fig. 1A and B): infection levels increased in fall and reached a plateau in November, decreased in winter because of the death of some infected plants, and increased from March to May, suggesting a two-step infection process related to the seasonal activity of aphid vectors. Relative infestation levels of barley plants by the three PAV vectors (R. padi, S. avenae, and $M$. dirhodum) pooled together (Fig. 1A and B) peaked in the fall, almost entirely due to $R$. padi in 1989 to 1990 and decreased in winter. A second period of aphid population increase occurred in spring, due to the three vector species. During the entire period, the shapes of infection and infestation curves were similar, with an advance of $\approx 350$ degree days for vector dynamics curves. In 1991 to 1992 , incidence of infection increased quickly during fall and reached $95 \%$ in December (Fig. 1C). Similarly, the incidence of aphids on plants in October was high ( $93 \%$ of plants infested by $R$. padi) but decreased rapidly in November and December. In this case, the PAV infection curve was monomodal and mainly due to a primary spread of the virus by very large populations of alate $R$. padi.

The dynamics of MAV serotypes (Fig. 2A) showed a monomodal pattern in 1989 to 1990, with very low levels of infection in fall and winter and an increase in spring, up to $80 \%$ of plants infected in May. In 1990 to 1991, the pattern was similar (Fig. 2B) but with a smaller increase in the percentage of infected plants in spring (up to $10 \%$ ). In 1991 to 1992, MAV infection levels were very low (3 to 5\%) with no spring increase (Fig. 2C). In most cases, MAV dynamics were consistent with that of its main vectors, i.e., S. avenae and M. dirhodum. The last two samples collected in spring 1991 were exceptions, in which levels of virus infection were higher than relative vector infestations previously recorded (Fig. 2B). This discrepancy could be due to a sampling error (very few plants were infested or infected) or an important vector activity, moving from plant to plant because of high spring temperatures. S. avenae and $M$. dirhodum were very rare in the field in fall and multiplied in spring much more in 1990 than in 1991. In 1991 to 1992, barley infestation by both aphid species reached $9 \%$ in October but decreased rapidly in fall and remained low the following spring (Fig. 2C). As a consequence, MAV infection levels were low with no spring increase.

The dynamics of RPV serotypes had no consistent pattern (Fig. 3). The percentages of plants infected by RPV were very low, without any obvious trend in 1990 to 1991 and 1991 to 1992 (Fig. 3B and C). In 1989 to 1990, levels of infection reached 10\% in December, with no further increase in spring (Fig. 3A). Primary introduction of RPV in the fields was low, even in the fall of 1991 when more than 
$90 \%$ of the plants were colonized by $R$. padi. The spread of RPV serotypes showed no consistent relationships with the dynamics of their vectors. In spring 1990, an increase in $R$. padi populations did not result in an increase in the proportion of infected plants.

As mentioned before, the most damaging part of the epidemics occurs in the fall: during this period, PAV constituted 97\%

Oct. Nov. Dec. Jan. Feb. Mar. Apr. May

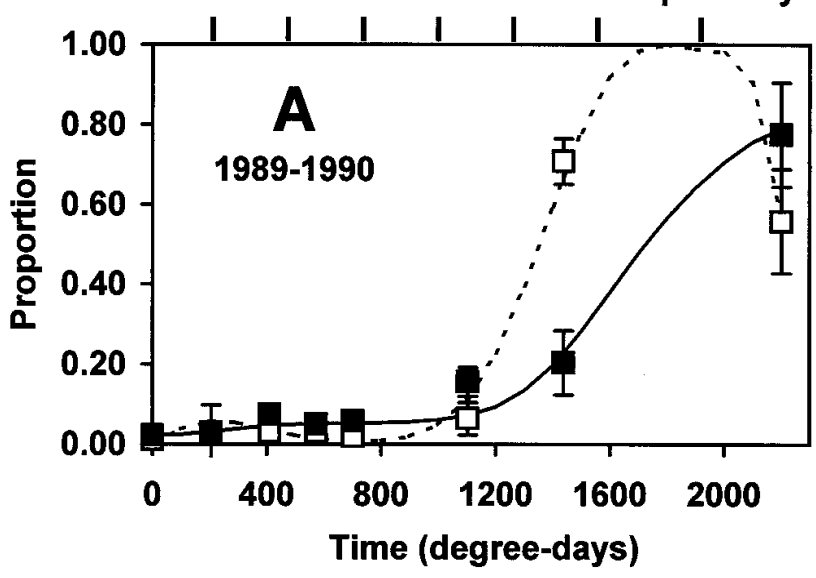

Oct. Nov. Dec. Jan. Feb. Mar. Apr. May

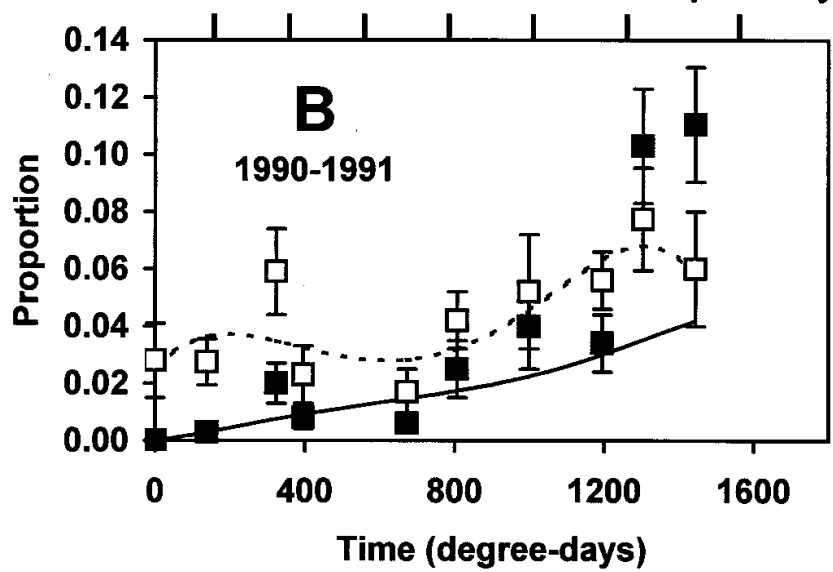

Oct. Nov. Dec. Jan. Feb. Mar. Apr. May

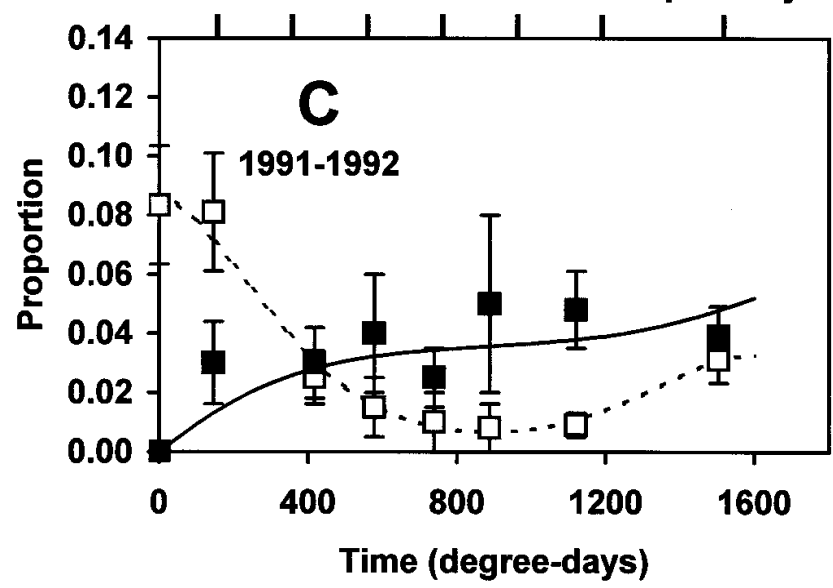

Fig. 2. Proportion of plants infected by Macrosiphum avenae virus (MAV) serotypes observed (black squares) and fitted (solid line) by the epidemiological model (equations in text). Proportion of plants infested by at least one of the two vector species, Sitobion avenae and Metopolophium dirhodum, observed (hollow squares) and interpolated (dashed line) by a fourth-degree polynomial. Upper abcissa: time in months; lower abcissa: time in degree days. Bars are standard deviations.
(December 1989), 75\% (December 1990), and 97\% (December 1991) of the total number of infected plants. Therefore, PAV can be considered responsible for most cases of plant death during winter. For this reason, only PAV-infected plants were taken into account in modeling for plant mortality assessment.
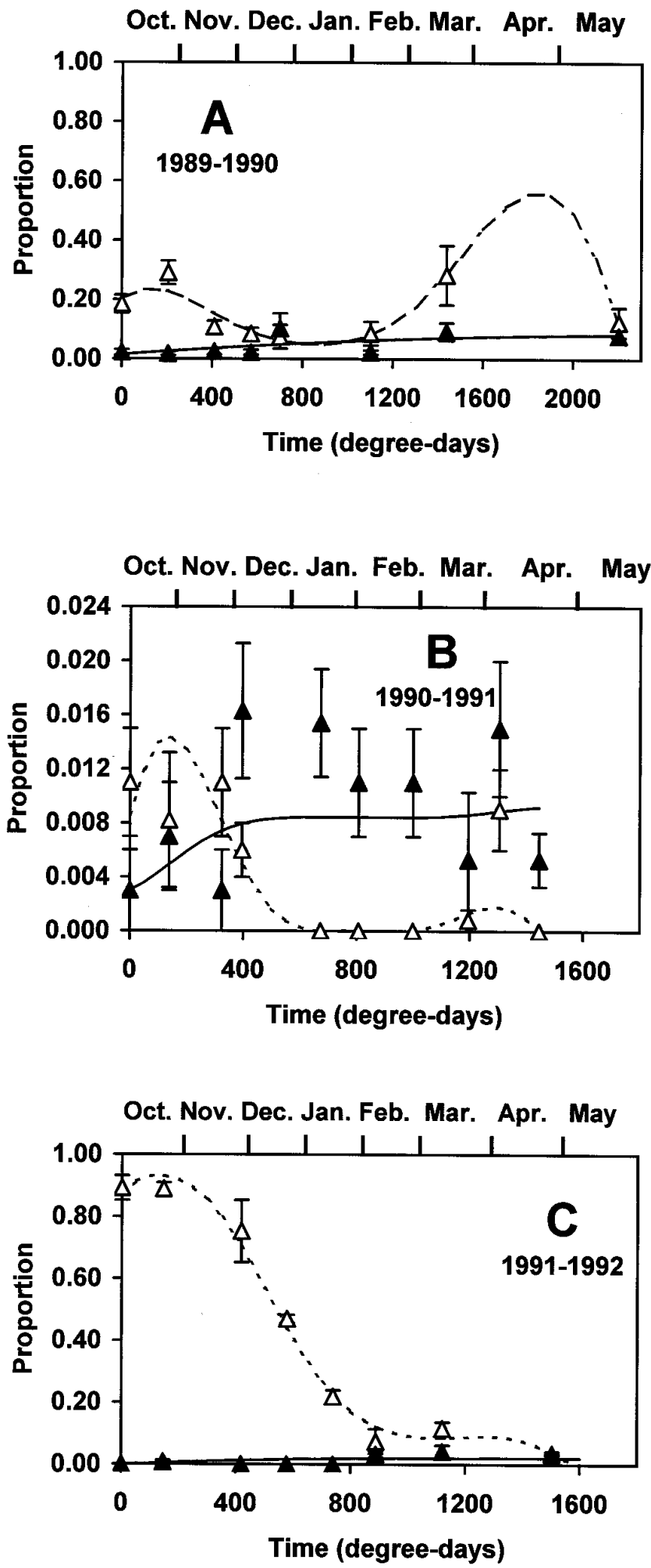

Fig. 3. Proportion of plants infected by Rhopalosiphum padi virus (RPV) serotypes observed (black triangles) and fitted (solid line) by the epidemiological model (equations in text). Proportion of plants infested by $R$. padi observed (hollow triangles) and interpolated (dashed line) by a fourth-degree polynomial. Upper abcissa: time in months; lower abcissa: time in degree days. Bars are standard deviations. 
Modeling results. Results of polynomial interpolations to simulate dynamics of aphid vectors are shown in Table 1 and Figures 1 to 3. Coefficients of determination were good for 1989 to 1990 and 1991 to 1992 but poor for 1990 to 1991 due to the third observation value that was particularly high compared with the others.

The three curves fitted for viral disease development for each year are presented in Figures 1 to 3, and their determination coefficients and parameter estimates are presented in Table 2.

For all 3 years, the model accurately described the progress of PAV serotype epidemics. For MAV and RPV, the results were less satisfactory (with the exception of MAV in 1989 to 1990) due to the scarcity of these serotypes and the consequent poor estimate of densities. Among the parameters estimated (Table 2), $c$ appears very stable across the years. The rate variable $\rho_{i}$ had different ranges of values depending on the serotype: twice as high for PAV (0.0017 to 0.0029) as for MAV (0.0007 to 0.0014) and much lower for RPV (0.00004 to 0.00005), except in 1990 to 1991 (0.001). The values of $h$ (310 to 550 degree days) were consistent with our observations of mortality under field conditions (1 to 3 months after initial infection). The value of the death rate $(\mu)$ could appear overestimated under the hypothesis of death rate being constant over the whole period (leading to 10 to $50 \%$ of death). According to our observations, it was indeed of that magnitude, but death seems likely from December to February; no death occurred after plants had reached the beginning of stem extension.

Death rate was estimated by its influence on the evolution of the proportion of infected plants. Because only infected plants were assumed to die, this proportion tended to decrease as the death rate increased. However, when $100 \%$ of the plants were infected, this value remained constant regardless of the death rate, because no recovering was allowed in the model. No death rate could be estimated when the percentage of infected plants was close to $100 \%$. This was the case in the 1991 to 1992 experiment, and the percentage of plants infected by PAV reached $95 \%$ in December.

Importance of mixed infections. Mixed infections with more than one serotype occurred in $27.5 \%$ of plants in 1989 to 1990 . In 1990 to 1991 and 1991 to 1992 , this proportion was $\approx 2$ and $\approx 3 \%$, respectively. In both 1989 to 1990 (Table 3) and 1990 to 1991 (results not shown), the percentage of plants with mixed infections decreased between December and February. This is consistent with the hypothesis that viral mixtures were particularly damaging

TABLE 1. Results of the interpolations (coefficients of determination $\left[R^{2}\right]$ ) on the proportion of plants infested by Metopolophium dirhodum, Sitobion avenae, and Rhopalosiphum padi $\left(\rho_{1}\right)$ by $M$. dirhodum and $S$. avenae $\left(\rho_{2}\right)$, or $R$. padi alone $\left(\rho_{3}\right)$

\begin{tabular}{lcccc}
\hline & & \multicolumn{3}{c}{ Coefficient of determination $^{\mathrm{b}}$} \\
\cline { 3 - 5 } Year & $N^{\mathrm{a}}$ & $\rho_{1}$ & $\rho_{2}$ & $\rho_{3}$ \\
\hline $1989-1990$ & 8 & 0.98 & 0.98 & 0.89 \\
$1990-1991$ & 10 & 0.56 & 0.62 & 0.75 \\
$1991-1992$ & 8 & 0.98 & 0.98 & 0.98 \\
\hline
\end{tabular}

a Observations per year.

b The phenomenological model fitted is $\rho_{i}(t)=\sin ^{2}\left(a_{4} t^{4}+a_{3} t^{3}+a_{2} t^{2}+a_{1} t^{1}+\right.$ $\left.a_{0}\right) ; a_{1}, a_{2}, a_{3}$, and $a_{4}$ are the coefficients of polynomial fitting and have no biological significance. Time $(t)$ is expressed on a degree-day scale (with $0^{\circ} \mathrm{C}$ as baseline temperature), $t=0$, first date of observation. to barley plants, resulting in increased mortality. In most cases, the mixed infections were of PAV and MAV and of PAV, MAV, and RPV, 60\% of MAV-infected plants in 1989 to $1990,13.4 \%$ in 1990 to 1991 , and $95 \%$ in 1991 to 1992 were coinfected by either PAV (mainly), RPV, or both. Of RPV-infected plants, $77.4 \%$ in 1989 to $1990,40 \%$ in 1990 to 1991 , and $97 \%$ in 1991 to 1992 were coinfected by either PAV, MAV, or both.

In most cases, mixed infections were more than twice as common as would be expected by chance. For the PAV-MAV association, $\chi^{2}=76.8(P<0.0001)$ in 1989 to 1990 and $\chi^{2}=4.2(P<$ $0.01)$ in 1990 to 1991 . For the PAV-RPV association, $\chi^{2}=146.2$ $(P<0.0001)$ in 1989 to 1990 and $\chi^{2}=8.9(P<0.0001)$ in 1990 to 1991. Finally, for the MAV-RPV association, $\chi^{2}=95.7(P<$ $0.0001)$ in 1989 to 1990 and $\chi^{2}=41.3(P<0.0001)$ in 1990 to 1991. For 1991 to $1992, \chi^{2}$ was not calculated because the percentage of plants infected by PAV rapidly reached $100 \%$.

\section{DISCUSSION}

This study presents three contrasting cases of overall disease patterns of BYDV governed by different ecological situations prevailing successively in fall, winter, and spring. A common trait of these patterns is that disease progress was consistently associated with the percentage of plants infested by aphids, which is a typical feature of vectorborne virus epidemiology (21). In the simplest case (1991 to 1992), many immigrating viruliferous aphids invaded the field in early fall and, probably by moving from plant to plant, led to $100 \%$ plant infection before the end of December, resulting in a monotonic disease progress curve. In the other years, disease progress curves included two modes, fall and spring, separated by a plateau in winter. In these latter cases, the levels of infection depended on the dynamics of each vector species during both periods. Many ecological factors were involved in both steps, but temperature had the strongest influence because it governed aphid survival and reproduction (6), the abundance of virus and vector reservoirs (14), and the impact of natural enemies.

This work is the first to demonstrate that under Western European conditions the dynamics of disease incidence caused by PAV-like serotypes is bimodal, with infection both in fall and spring, whereas MAV-like serotypes are strongly associated with spring infections. That infection by RPV-like serotypes are very

TABLE 3. Mixed infections by serotypes of Barley yellow dwarf virus in a winter barley field (Le Rheu, western France) ${ }^{\mathrm{a}}$

\begin{tabular}{lccccc}
\hline 1989-1990 & $\begin{array}{c}\text { PAV }+ \\
\text { MAV }\end{array}$ & $\begin{array}{c}\text { PAV }+ \\
\text { RPV }\end{array}$ & $\begin{array}{c}\text { MAV }+ \\
\text { RPV }\end{array}$ & $\begin{array}{c}\text { PAV }+ \\
\text { MAV + RPV }\end{array}$ & $\begin{array}{c}\text { Overall mixed } \\
\text { infections }\end{array}$ \\
\hline 5 Oct. & 0 & 0 & 2 & 1 & 10 \\
18 Oct. & 1 & 0 & 0 & 1 & 3.2 \\
31 Oct. & 13 & 1 & 0 & 0 & 16.7 \\
16 Nov. & 8 & 3 & 1 & 4 & 16.7 \\
12 Dec. & 19 & 6 & 2 & 24 & 51 \\
1 Feb. & 8 & 1 & 1 & 2 & 11.4 \\
9 Mar. & 1 & 5 & 8 & 24 & 33.3 \\
16 May & 180 & 0 & 3 & 6 & 53 \\
\hline
\end{tabular}

${ }^{\mathrm{a}}$ Number of infected plants. PAV = Padi avenae virus; MAV = Macrosiphum avenae virus; $\mathrm{RPV}=$ Rhopalosiphum padi virus .

b Percent total infected plants.

TABLE 2. Results of fitting the model to observed data on incidence of barley plants infected with Padi avenae virus (PAV), Macrosiphum avenae virus (MAV), and Rhopalosiphum padi virus (RPV) serotypes of Barley yellow dwarf virus

\begin{tabular}{|c|c|c|c|c|c|c|c|c|c|c|}
\hline \multirow[b]{2}{*}{ Year } & \multicolumn{4}{|c|}{ Coefficient of determination $\left(R^{2}\right)$} & \multicolumn{6}{|c|}{ Parameter estimates $^{\mathrm{a}}(\mathrm{SD})$} \\
\hline & Overall & PAV & MAV & RPV & $\rho_{1}$ & $\rho_{2}$ & $\rho_{3}$ & $c$ & $\mu$ & $h$ \\
\hline 1989 & 0.621 & 0.958 & 0.842 & 0. & $17(0.000$ & $14(0.0)-x)$ & $0.00005(0$. & $1.3(0$ & $2(0$. & $550(75.5)$ \\
\hline 1990 & 0.390 & 0.862 & 0.431 & 0.316 & $0.0029(0.00035)$ & $0.0007(0.00017)$ & $0.001(0.00029)$ & $1.3(0.78)$ & $0.0028(0.0003)$ & $310(54.8)$ \\
\hline
\end{tabular}

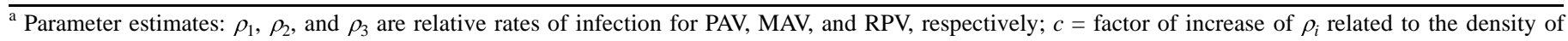
nearby infected plants; $\mu=$ rate of plant death; and $h=$ delay from infection to plant death in degree days (equations in text). 
limited and apparently occur in the fall confirms the previous work of Lister and Sward (31) in America. This can be explained by the population dynamics of the most efficient vectors of each serotype. In most parts of Western Europe, fall flights of cereal aphids consist mainly of $R$. padi. These flights are usually a mixture of virginoparae, gynoparae, and males, and the most frequent serotype carried is PAV (30). The occasional transmission of MAV serotypes by $R$. padi seems to be due mainly to heterologous encapsidation of MAV-RNA by PAV or RPV when mixed infections of MAV and PAV or RPV occur, although rare cases of transmission of MAV alone by $R$. padi have been reported $(16,30)$ and could depend on the aphid clones involved (45). In the fall, few $S$. avenae and $M$. dirhodum are caught in suction traps compared with $R$. padi. Not surprisingly, few crops are infected with MAV at this time. The relative rarity of RPV serotypes in spite of the abundance of its vector is probably caused by the fact that in western France the main reservoir of RPV is Lolium spp. (20), which are not favored hosts for $R$. padi.

During winter, populations of parthenogenetic aphids are differentially affected by low temperatures (19). $R$. padi is more susceptible to frost than the other species and has a slower rate of increase than $S$. avenae and especially $M$. dirhodum at temperatures below $15^{\circ} \mathrm{C}(6)$. As a consequence, $M$. dirhodum and $S$. avenae populations generally multiply earlier and reach larger numbers than $R$. padi in the spring, resulting in an increase in MAV and PAV incidence but inconsistent RPV progress, which is completely dependent on $R$. padi. Nevertheless, this argument failed in spring 1990 when an increase in the spring populations of $R$. padi had no influence on the spread of RPV; further experiments are needed to explain this, especially on the transmissibility of some French RPV serotypes from and to barley plants at different growth stages. One hypothesis could be that some barley cultivars (e.g., cv. Express) become less susceptible to RPV transmission with time.

Fall infections of winter cereals are much more damaging than spring infections, because BYDV may severely reduce the winter survival of infected plants by causing a rise of 4 to $8^{\circ} \mathrm{C}$ in the temperature threshold, at which $50 \%$ of the plants are killed by frost (34), while plants infected later are not exposed to frost and generally survive. As a consequence, PAV, detected in more than $90 \%$ of barley samples infected from October to December, is by far the most damaging and epidemiologically important serotype under the conditions in western France.

Mixed infections can also be especially damaging (24). They are frequent in the fields and vary by years (15). Our results suggest that cross-protection is not an important factor limiting superinfection and agree with those of Clement et al. (3) and Gildow et al. (10) who found $16 \%$ and up to $8 \%$ of plants containing two serotypes in field surveys of cereals in Pennsylvania and Indiana, respectively. The proportion of multiple infections shows that they are, in most cases, more frequent than expected if the hypothesis of independent transmissions is correct. These results are consistent with transmission tests with alate aphids captured alive (30) and with results from heterologous encapsidation studies (23). Heterologous encapsidation, demonstrated previously in the laboratory (44), apparently occurs frequently in the field. It is thought to give a selective advantage to viral mixtures because opportunities for transmission by aphids are enhanced when the principal vector species is absent.

Our study has stressed the complexity of interrelations between the three serotypes. A refined analysis is required to assess with greater accuracy the impact on viral dynamics of multiple transmission (assumed here to be related to heterologous encapsidations) and the possible influence of multiple infections on the plants death.

The first result of our descriptive model is to stress the close relationships between BYDV serotype and vector dynamics. This confirms the overall accuracy of the vectotype classification of Rochow $(40,41)$ in BYD epidemiology, and in maritime climates, an index based on field populations of aphids that have already colonized cereals may be a better predictor of potential virus spread than aerial density of vectors (26). Moreover, the stability of parameter $c$ from year to year makes it possible to use the model as a first step to a forecasting tool. The $\rho_{i}$ parameters are the most variable but fall in a fairly narrow range for PAV and MAV, they could be considered as an index of overall infectiousness of aphids landing on the crop, depending on the year and they could be assessed by measuring flying aphid infectivity (36). Nevertheless, the $\rho_{i}$ parameters do not take into account variations in flight activity of alates in the field, determined mainly by temperature and rain, which could modify the primary spread of viruses. To clarify the relationship, this has to be modeled mechanistically, as Kendall et al. (25) did for overall BYDV transmissions. Finally, such a model could not simply take into account mixed infections, the importance of which was pointed out in our paper. To do so, eight equations instead of four would be necessary, which could only be resolved by increasing significantly the number of sampling points, i.e., by undertaking further experiments. To improve the reliability of the model, a detailed study of the mortality process (rate, incubation duration, influence of serotypes involved, influence of host-plant phenological stage) is also required.

However, in spite of its simplicity, the model has demonstrated its ability to account for the kinetics of the disease with good accuracy. It required the estimation of a small number of parameters, and the spread of the epidemic was dependent on only two main variables: temperature and proportions of plants infested by vectors. It suggested that further development of an accurate forecasting tool will rely mainly on the ability of forecasting cereal aphid population dynamics.

\section{ACKNOWLEDGMENTS}

This work was supported by a grant from Bayer-France. We are grateful to J. S. Pierre for advice on modeling and R. T. Plumb for constructive criticism and detailed reviews of the manuscript.

\section{LITERATURE CITED}

1. Baltenberger, D. E., Ohm, H. W., and Foster, J. E. 1987. Reactions of oat, barley, and wheat to infection with barley yellow dwarf virus isolates. Crop Sci. 27:195-198.

2. Chay, C. A., Smith, D. M., Vaughan, R., and Gray, S. M. 1996. Diversity among isolates within the PAV serotype of barley yellow dwarf virus. Phytopathology 86:370-377.

3. Clement, D. L., Lister, R. M., and Foster, J. E. 1986. ELISA-based studies on the ecology and epidemiology of barley yellow dwarf virus in Indiana. Phytopathology 76:86-92.

4. Creamer, R., and Falk, B. W. 1989. Characterization of a nonspecifically aphid-transmitted CA-RPV isolate of barley yellow dwarf virus. Phytopathology 79:942-946.

5. D'Arcy, C. J., and Mayo, M. 1997. Proposal for changes in luteovirus taxonomy and nomenclature. Arch. Virol. 142:1285-1287.

6. Dean, G. J. W. 1974. Effect of temperature on the cereal aphids Metopolophium dirhodum Wlk., Rhopalosiphum padi L., and Macrosiphum avenae F. (Hem. Aphididae). Bull. Entomol. Res. 63:401-409.

7. Dedryver, C. A., and Gellé, A. 1982. Biologie des pucerons des céréales dans l'Ouest de la France. IV: Etude de l'hivernation des populations anholocycliques de Rhopalosiphum padi L., Metopolophium dirhodum Wlk. et Sitobion avenae F., sur repousses de céréales dans trois stations de Bretagne et du Bassin Parisien. Acta. Oecol. Appl. 3:321-342.

8. Domier, L. L. 1995. Genome, structure, and function of barley yellow dwarf viruses. Pages 181-201 in: Barley Yellow Dwarf 40 Years of Progress. C. J. D'Arcy and P. A. Burnett, eds. The American Phytopathological Society, St. Paul, MN.

9. Gildow, F. E., and Franck, J. A. 1988. Barley yellow dwarf virus in Pennsylvania: Effect of the PAV isolate on yield components of Noble spring oats. Plant Dis. 72:254-256.

10. Gildow, F. E., Franck, J. A., Bingaman, D., and Powell, C. 1987. Barley yellow dwarf virus in small grains of Pennsylvania: Isolate identification, distribution, and vector efficiency. Plant Dis. 71:922-926. 
11. Gill, C. C., and Chong, J. 1976. Differences in cellular ultrastructural alterations between variants of barley yellow dwarf virus. Virology 75:33-47.

12. Gill, C. C., and Chong, J. 1979. Cytopathological evidence for the division of barley yellow dwarf virus isolates into two subgroups. Virology 95:59-69.

13. Gill, C. C., and Comeau, A. 1977. Synergism in cereals corn leaf aphid specific and aphid nonspecific isolates of barley yellow dwarf virus. Phytopathology 67:1388-1392.

14. Gillet, H., Dedryver, C. A., Robert, Y., Gamon, A., and Pierre, J. S. 1990. Assessing the risk of primary infection of cereals by barley yellow dwarf virus in autumn in the Rennes basin of France. Ann. Appl. Biol. 117:237-251.

15. Griesbach, J. A., Falk, B. W., and Valverde, R. A., 1990. Incidence of barley yellow dwarf viruses in California cereals. Plant Dis. 74:111-114.

16. Guo, J. Q., Moreau, J. P., and Lapierre, H. 1996. Variability among aphid clones of Rhopalosiphum padi L. and Sitobion avenae F. (Homoptera: Aphididae) in transmission of three PAV isolates of barley yellow dwarf viruses. Can. Entomol. 128:209-217.

17. Halbert, S. E., Connelly, B. J., Bishop, G. W., and Blackmer, J. L. 1992. Transmission of barley yellow dwarf virus by field collected aphids (Homoptera: Aphididae) and their relative importance in barley yellow dwarf epidemiology in southwestern Idaho. Ann. Appl. Biol. 121:105121.

18. Halbert, S. E., Connelly, B. J., Lister, R. M., Klein, R. E., and Bishop, G. W. 1992 Vector specificity of barley yellow dwarf virus serotypes and variants in southwestern Idaho. Ann. Appl. Biol. 121:123-132.

19. Hand, S. C. 1989. The overwintering of cereal aphids on gramineae in southern England, 1977-1980. Ann. Appl. Biol. 115:17-29.

20. Henry, M., Dedryver, C. A. 1991. Occurrence of barley yellow dwarf virus in pastures of western France. Plant Pathol. 40:93-99.

21. Irwin, M. E., and Thresh, J. M. 1990. Epidemiology of barley yellow dwarf: A study in ecological complexity. Annu. Rev. Phytopathol. 28: 393-424.

22. Jenkins, G. 1966. Comparison of tolerance to barley yellow dwarf virus in barley and oats. Ann. Appl. Biol. 57:163-168.

23. Johnstone, G. R., and Guy, P. L. 1986. Epidemiology of viruses transmitted persistently by aphids. Pages 1-7 in: Proceeding of the Third International Plant Virus Epidemiology Workshop. O. W. Barnett, ed. Orlando.

24. Johnstone, G. R., Sward, R. J., Farrell, J. A., Greber, R. S., Guy, P. L., McEvan, J. M., and Waterhouse, P. M. 1990. Epidemiology and control of barley yellow dwarf viruses in Australia and New Zealand. Pages 228239 in: World Perspectives on Barley Yellow Dwarf. P. A. Burnett, ed. International Maize and Wheat Improvement Center, Mexico, D.F.

25. Kendall, D. A., Brain, P., and Chinn, N. E. 1992. A simulation model of the epidemiology of barley yellow dwarf virus in winter sown cereals and its application to forecasting. J. Appl. Ecol. 29:414-426.

26. Kendall, D. A., and Chinn, N. E. 1990. A comparison of vector population indices for forecasting barley yellow dwarf virus in autumn sown cereal crops. Ann. Appl. Biol. 116:87-102.

27. Kendall, D. A., and Smith, B. D. 1981. The significance of aphid monitoring in improving barley yellow dwarf virus control. Pages 399403 in: Proceedings 1981 British Crop Protection Conference: Pests and Diseases. Brighton, U.K.

28. Kermack, W. D., and McKendrick, A. G. 1927. A contribution to the mathematical theory of epidemics. JR Statist. Soc. Serie A 115:700-721.
29. Leclercq-Le Quillec, F. 1992. Analyse de la dynamique spatiotemporelle du complexe BYDV (barley yellow dwarf virus) et effet d'un traitement de semences sur la distribution des vecteurs et des virus. Thèse de doctorat. University of Paris, Paris.

30. Leclercq-Le Quillec, F., Tanguy, S., and Dedryver, C. A. 1995. Aerial flow of barley yellow dwarf viruses and of their vectors in western France. Ann. Appl. Biol. 126:75-90.

31. Lister, R. M., and Sward, R. J. 1988. Anomalies in serological and vector relationships of MAV isolates of barley yellow dwarf virus from Australia and the U.S.A. Phytopathology 78:766-770.

32. MacElhany, P., Real, L. A., and Power, A. G. 1995. Vector preference and disease dynamics, a study of Barley yellow dwarf virus. Ecology 76:444-457.

33. Mastari, J., Lapierre, H., and Dessens, J. T. 1998. Asymetrical distribution of barley yellow dwarf virus PAV variants between host plant species. Phytopathology 88:818-821.

34. Paliwal, Y. C., and Andrews, C. J. 1990. Barley yellow dwarf virus-host plant interactions affecting winter stress tolerance in cereals. Pages 313320 in: World Perspectives on Barley Yellow Dwarf. P. A. Burnett, ed. International Maize and Wheat Improvement Center, Mexico, D.F

35. Pead, M. T., and Torrance, L. 1988. Some characteristics of monoclonal antibodies to a British MAV-like isolate of barley yellow dwarf virus. Ann. Appl. Biol. 113:639-644.

36. Plumb, R. T. 1976. Barley yellow dwarf virus in aphids caught in suction traps 1969 to 1973. Ann. Appl. Biol. 83:53-59.

37. Plumb, R. T. 1983. Barley yellow dwarf virus: A global problem. Pages 185-198 in: Plant Virus Epidemiology. R. T. Plumb and J. M. Thresh, eds. Blackwell Scientific Publications, Oxford.

38. Plumb, R. T. 1990. The epidemiology of barley yellow dwarf in Europe. Pages 215-227 in: World Perspectives on Barley Yellow Dwarf. P. A. Burnett, ed. International Maize and Wheat Improvement Center, Mexico, D.F.

39. Ranieri, R., Mezzalama, M., Burnett, P. A., and Lister, R. M. 1993. Seasonal occurrence of barley yellow dwarf virus serotypes in smallgrain cereals in the Valley of Mexico. Plant Dis. 77:623-626.

40. Rochow, W. F. 1969. Biological properties of four isolates of barley yellow dwarf virus. Phytopathology 59:1580-1589.

41. Rochow, W. F. 1970. Barley yellow dwarf virus. No. 32 in: Descriptions of Plant Viruses. Commonw. Mycol. Inst./Assoc. Appl. Biol., Kew, England.

42. Rochow, W. F. 1970 . Barley yellow dwarf virus: Phenotypic mixing and vector specificity. Science 167:875-878.

43. Rochow, W. F., and Carmichael, L. E. 1979. Specificity among barley yellow dwarf viruses in enzyme immunosorbent assays. Virology 95:415-420.

44. Rochow, W. F., and Pang, E. W. A. 1961. Aphids can acquire strains of barley yellow dwarf virus they do not transmit. Virology 15:382-384.

45. Sadeghi, E., Dedryver, C. A., Riault, G., and Gauthier, J. P. 1997. Variation in transmission of two BYDV-MAV isolates by multiple clones of Rhopalosiphum padi L. Eur. J. Plant Pathol. 103:515-519.

46. Torrance, L., Pead, M. T., Larkins, A. P., and Butcher, G. W. 1986. Characterization of monoclonal antibodies to a U.K. isolate of barley yellow dwarf virus. J. Gen. Virol. 67:549-556.

47. Vincent, J. R., Lister, R. M., Ueng, P. P., Wen, F., Lei, C. H., Klein, R. E., and Larkins, B. A. 1990. Genomic organization of barley yellow dwarf viruses. BYDV Newsl. 3:34-37. 